\title{
Antimicrobial activity of hemocompatible silver doped hydroxyapatite nanoparticles synthesized by modified sol-gel technique
}

\author{
Sushma Jadalannagari · Ketaki Deshmukh • \\ Sutapa Roy Ramanan • Meenal Kowshik
}

Received: 17 October 2012/Accepted: 22 October 2012/Published online: 6 February 2013

(c) The Author(s) 2013. This article is published with open access at Springerlink.com

\begin{abstract}
Silver doped hydroxyapatite $\left(\mathrm{Ag}_{x} \mathrm{Ca}_{100-x}\left(\mathrm{PO}_{4}\right)_{6}\right.$ $(\mathrm{OH})_{2}$ ) nanorods were synthesized using a modified sol gel method at a low temperature of $100{ }^{\circ} \mathrm{C}$. Silver concentration was varied as $x=1,3$ and 5 . X-ray diffraction studies showed that the synthesized silver doped hydroxyapatite (Ag-HAp) was fully crystalline with hexagonal structure and an average crystallite size of $25 \mathrm{~nm}$. At all the doping concentrations, the nanoparticles were rod shaped with an average length of $110-180 \mathrm{~nm}$ and diameter of $20-25 \mathrm{~nm}$ as determined from transmission electron microscopy (TEM) studies. These compounds were tested for their antimicrobial activities against $E$. coli (MTCC 2345) and S. aureus (MTCC 737). Antimicrobial activity was observed for all the three silver doping concentrations with the highest activity for $x=3$, in terms of the zone of inhibition and the percentage reduction in the number of colonies. Hemolysis ratios for $x=1$ and 3 Ag-HAp samples were below $2 \%$, indicating that they are highly hemocompatible and can be a promising biomaterial for tissue engineering applications in orthopedics.
\end{abstract}

The authors, S. Jadalannagari and K. Deshmukh contributed equally.

S. Jadalannagari $\cdot$ K. Deshmukh $\cdot$ M. Kowshik $(\bowtie)$

Biological Sciences Department, Birla Institute of Technology

and Science Pilani, K K Birla Goa Campus,

Zuarinagar 403726, Goa, India

e-mail: meenal@goa.bits-pilani.ac.in

S. Jadalannagari

e-mail: Sushmajp5@gmail.com

K. Deshmukh

e-mail: Ketaki03@gmail.com

\section{S. R. Ramanan ( $\square)$}

Chemical Engineering Department, Birla Institute of Technology and Science Pilani, K K Birla Goa Campus,

Zuarinagar 403726, Goa, India

e-mail: sutapa@goa.bits-pilani.ac.in
Keywords Hydroxyapatite - Silver doping . Antimicrobial activity $\cdot$ Hemocompatibility

\section{Introduction}

Hydroxyapatite (HAp) is a calcium phosphate ceramic material which has similarity to human bone composition and the ability to form a strong bond to human hard tissue (Ramanan and Venkatesh 2004). Due to its high osteoconductive properties, porosity, and longer degradation times, it finds application as an attractive implant material; as filler in dental prosthesis, for reconstructing bone defects, as thin coatings on metals like titanium or CoCrMo alloys for hip and knee prosthesis (Diaz et al. 2009). Its high biocompatibility, allows tissue to infiltrate and chemically bond with it. The success of these orthopedic and dental implants is dependent on implant osteointegration, but the long term survival is dependent on its resistance to bacterial infections (Chen et al. 2006). A disadvantage of HAp is that, proteins, amino acids, and other organic substances are easily adsorbed, which could create an environment conducive for the growth of bacteria on its surface leading to infection at the implant site, accompanied by decreased penetration of antibiotics and reduced blood supply (Rameshbabu and Prasad Rao 2007). When microorganisms adhere onto implant surfaces, they can form biofilms wherein microorganisms tend to be more resistant to antimicrobial agents (Stanic et al. 2011). In addition, the presence of implant materials inside the body interferes with the host defense mechanism and influences the clinical dose of antibiotics that is needed to protect against infections. Moreover, antibiotics loaded in the implant material tend to be quickly washed out by body fluids and cannot prevent long term post surgical infections 
(Stanic et al. 2011; Bahadir et al. 2009). Besides, excessive use of antibiotics could lead to the development of resistant microorganisms. In view of this, use of inorganic antibacterial agents has attracted interest for control of microbial infections. Doping HAp with antimicrobial metal ions has been exploited to address these issues (Rameshbabu and Prasad Rao 2007; Stanic et al. 2011; Xiao et al. 2010; Kim et al. 2011).

Transition metal ions like silver, zinc and copper have stronger antibacterial properties than other metallic ions (Gristina and Costerton 1985). Silver ions in particular exhibit oligodynamic activity with a broad spectrum of antibacterial susceptibility which is particularly effective against the polymicrobial colonization associated with biomaterial infection (Gristina and Costerton 1985; Kramer et al. 1981) Silver containing antimicrobial biomaterials have silver in the form of elemental silver or Ag ions incorporated into organic (polymers) or inorganic (bioglasses and HAp) matrices (Diaz et al. 2009). Ag ions released from matrices are absorbed into the surface of negatively charged bacterial cell walls due to electrostatic attraction leading to the disruptions of the cell wall and cell membrane (Woo et al. 2008). It also forms stable bonds with thiol group $(-\mathrm{SH})$ containing proteins in the cell membrane including enzymes involved in trans-membrane energy generation and ion transport (Bragg and Rainnie 1974; Furr et al. 1994). Thus, silver catalyzed formation of disulfide bonds can change protein structure and deactivate important enzymes such as those involved in cellular respiration (Schreus and Rosenberg 1982). In addition it interacts with phosphate groups of DNA, resulting in bacterial degeneration and loss of ability to replicate (Feng et al. 2000). It is also known to promote the formation of reactive oxygen species (ROS) inside bacterial cells which can cause significant damage to cells ultimately leading to cell death. (Woo et al. 2008; Furr et al. 1994; Schreus and Rosenberg 1982; Feng et al. 2000) Thus, it has recently become one of the preferred ions to confer microbial resiliency on biomaterials and medical devices (Gristina and Costerton 1985). Several in vitro studies have reported that silver ions in HAp play an important role in preventing or minimizing initial bacterial adhesions (Mo et al. 2008; Chen et al. 2008).

Silver hydroxyapatite (Ag-HAp) has been synthesized using various starting materials and calcination temperatures in the range of 100 to $900{ }^{\circ} \mathrm{C}$ by different methods such as powder processing, sol gel, microwave processing etc. (Diaz et al. 2009; Rameshbabu and Prasad Rao 2007; Stanic et al. 2011; Zheng et al. 2009). In this study crystalline Ag-HAp nanorods have been synthesized at $100{ }^{\circ} \mathrm{C}$ using a modified sol-gel method followed by dialysis (Jadalannagari et al. 2011). This material exhibits good antimicrobial activity against $E$. coli and $S$. aureus, along with good hemocompatibility, and therefore could be a potential candidate for bone tissue engineering applications (Chen et al. 2006).

\section{Materials and methods}

Preparation of the materials

Ag-HAp was prepared using $\mathrm{CaCl}_{2} \cdot 2 \mathrm{H}_{2} \mathrm{O}$ (Hi-Media), $\mathrm{H}_{3} \mathrm{PO}_{4}$ (Merck), triethylamine (Merck), $\mathrm{AgNO}_{3}$ (HiMedia) and de-ionized water as starting materials (Jadalannagari et al. 2011). The concentration of $\mathrm{Ag}$ was varied as $x=1,3$ and 5, in $\left(\mathrm{Ag}_{x} \mathrm{Ca}_{100-x}\left(\mathrm{PO}_{4}\right)_{6}(\mathrm{OH})_{2}\right)$. Required amount of silver nitrate was added to $2 \mathrm{M}$ calcium chloride solution in de-ionized water under continuous stirring in dark. $1 \mathrm{M}$ phosphoric acid in triethylamine was added drop-wise to the above solution. $(\mathrm{Ca}+\mathrm{Ag})$ : $\mathrm{P}$ atomic ratio was maintained at 1.67 . The $\mathrm{pH}$ was adjusted to 10.0 using liquid ammonia and stirring was continued till the completion of gel formation. The gel obtained was dialyzed (using dialysis bag, Bangalore Genie 110) against de-ionized water for $12 \mathrm{~h}$ with frequent change of water for active removal of adsorbed ions (Jadalannagari et al. 2011). The dialyzed samples were dried in a hot air oven (Quality instruments) at $100{ }^{\circ} \mathrm{C}$ for $48 \mathrm{~h}$ and the samples were powdered using an agate mortar and pestle.

\section{Characterization of the materials}

X-ray diffraction (XRD) studies of the powdered samples were carried out for phase identification using X-Ray Diffractometer (Miniflex II Rigaku) with monochromatic $\mathrm{CuK}_{\alpha}$ radiation $(\lambda=1.5405 \AA)$ and a scan range of $2 \theta=20^{\circ}$ to $80^{\circ}$. The crystallite sizes were determined using Scherrer's equation, $D=\frac{k \lambda}{\beta \cos \theta}$; where $D$ is the crystallite size, $k$ the shape constant (0.9), $\lambda$ is the X-ray $\left(\mathrm{CuK}_{\alpha}\right)$ wavelength, $\theta$ the diffraction angle in degrees and $\beta$ (in radians) is the half width measured for the [211] peak. The crystal lattice parameters, $a$ and $c$, were calculated using the formula.

$\frac{1}{d_{h k l}^{2}}=\left[\frac{4}{3}\left(h^{2}+k^{2}+h k\right)+l^{2}\left(\frac{a}{c}\right)^{2}\right] \frac{1}{a^{2}}$

where, $d$ is obtained from the formula, $d=\frac{n \lambda}{2 \times \sin \theta}$

The degree of crystallinity $(X c)$, corresponding to [002] peak was determined using the relation,

$X c=\left(\frac{k}{\beta_{002}}\right)^{3}$, where $k$ is a constant, with a value of 0.24 for HAp (Landi et al. 2000).

The particle shape and size of Ag-HAp were studied using transmission electron microscope (TEM) (Phillips CM 200). The functional groups present in the 'as synthesized' compounds were ascertained by Fourier 
Transform Infrared Spectroscopy (FTIR 8201 PC Shima$\mathrm{dzu}$ ), over the region $450-4,000 \mathrm{~cm}^{-1}$. The pellets for analysis were obtained by mixing $1 \mathrm{mg}$ of the powdered samples with spectroscopic grade $\mathrm{KBr}$ (Merck).

\section{Studies on antimicrobial activity}

Antimicrobial activities of the Ag-HAp powders were investigated against $E$. coli (MTCC 2345) and S. aureus (MTCC 737) by agar diffusion assay and Resazurin Microtitre Assay (REMA) (Sarker and Nahar 2007). The initial concentration of the microorganisms used was $1 \times 10^{8}$ cells $/ \mathrm{ml}$ (test culture).

The agar diffusion assay was performed on MuellerHinter $(\mathrm{MH})$ agar. $1 \%$ test culture was seeded into the medium before pouring it into sterile petri plates to form a layer of $4 \mathrm{~mm}$ thickness. $200 \mu \mathrm{g} / \mathrm{ml}$ of 1,3 and $5 \% \mathrm{Ag}-$ HAp was loaded on sterile discs (Himedia) which were placed on the $\mathrm{MH}$ agar plates and incubated for $24 \mathrm{~h}$ at $37^{\circ} \mathrm{C}$. The results were recorded by observing the zone of inhibition.

Quantitative tests for measuring the minimum inhibitory concentration (MIC) and minimum bactericidal concentration (MBC) were performed in 96 well microtitre plates using the resazurin dye. The Ag-HAp powders were added to $100 \mu \mathrm{l}$ of $2 \times \mathrm{MH}$ media, $2 \mu \mathrm{l}$ of test culture $(1 \%)$, $10 \mu \mathrm{l}$ resazurin dye and the final volume was made up to $200 \mu \mathrm{l}$ using sterile distilled water. The plates were incubated in dark on a shaking incubator for $24 \mathrm{~h}$ at $37^{\circ} \mathrm{C}$. Undoped HAp was used as a control. After $24 \mathrm{~h}$, the culture from the wells was plated onto nutrient agar plates and the concentration at which no growth was obtained was recorded as the $\mathrm{MBC}$ value. The test was performed in triplicates for each of the 1, 3 and $5 \% \mathrm{Ag}$ doping. Same set of experiments were performed using M9 minimal media (Sambrook and Russell 2001).

Kill curve analysis was performed to determine the time taken for the total reduction of cell number at $\mathrm{MBC}$ concentration. The study was performed using $5 \mathrm{ml} \mathrm{MH}$ broth to which required amount of Ag-HAp and $1 \%$ of the test culture was added. The solution was kept under stirring; samples were withdrawn at regular intervals, and spread plated on nutrient agar plates after appropriate dilution. The number of colony forming units on the plate was counted after $24 \mathrm{~h}$ of incubation at $37^{\circ} \mathrm{C}$.

\section{Hemolysis test}

The hemolytic activity of the samples was investigated according to the method described by Parnham, Yinghui et al. (Landi et al. 2000; Sarker and Nahar 2007). Sterile saline solution $(1.25 \mathrm{ml})$ was added to $1 \mathrm{mg}$ of $\mathrm{Ag}-\mathrm{HAp}$; $4 \mathrm{ml}$ blood was collected from a healthy human and diluted with $5 \mathrm{ml}$ of sterile saline solution; $20 \mu \mathrm{l}$ of the diluted blood was then added to the tubes containing $1 \mathrm{mg} / \mathrm{ml}$ of Ag-HAp in sterile saline solution and incubated at $37{ }^{\circ} \mathrm{C}$ for $30 \mathrm{~min}$. Subsequently, the tubes were incubated for $60 \mathrm{~min}$ in water bath shaker at $37^{\circ} \mathrm{C}$ and centrifuged at $700 \times g$ for $10 \mathrm{~min}$ sterile saline solution and distilled water were used as the negative and positive controls, respectively. The amount of free hemoglobin was determined by measuring the absorbance of the supernatant at $540 \mathrm{~nm}$ (UV Spectrophotometer Shimadzu UV 2450). The hemolysis rate (HR) was calculated using (Zheng et al. 2009):

$H R=\frac{D t-D n c}{D p c-D n c} \times 100 \%$,

where $D t, D n c$ and $D p c$ are the absorbance of the sample, negative control and positive control, respectively. All the experiments were run in triplicate.

Silver ion release studies

The Ag-HAp samples were suspended in simulated body fluid (SBF) at the concentration of $1 \mathrm{mg} / \mathrm{ml}$ in brown bottles. SBF was prepared according to the Cuneyt Tas method (Tas 2000). The samples were sonicated (Microson ${ }^{\mathrm{TM}}$ Sonicator) for $30 \mathrm{~min}$ at 3 RPS (Rotation per second), followed by centrifugation (Eppendorf 5415R) at 12,000 rpm for $30 \mathrm{~min}$ and the supernatant was used to analyze the silver ion using ICP-MS (LAM-MC-ICP-MS).

\section{Results and discussion}

The synthesized Ag-HAp nanoparticles were elongated and rod like in morphology. Most methods for HAp synthesis are elaborate and require long processing hours as well as presence of various organic chelating agents (Stanic et al. 2011; Bahadir et al. 2009). In the present study dialysis was used for the active removal of the adsorbed ions and thus, pure Ag-HAp nanorods were obtained by heating at $100{ }^{\circ} \mathrm{C}$ in hot air oven. It has been reported that high temperature processing of silver and silver-doped polymer films led to increase in crystallinity and migration of $\mathrm{Ag}^{+}$ions into the bulk, resulting in reduction in silver release kinetics (Babapour et al. 2006; Hyung et al. 2003). For practical applications controlled silver release can increase stability of the medical implant due to sustained antimicrobial activity. Hence, low temperature synthesis of silver doped materials, can be a solution to this problem.

The XRD spectra of the Ag-HAp (1, 3 and $5 \%$ ) and HAp are shown in Fig. 1. The samples with silver content $x=3$ and 5 exhibited a shoulder at $2 \theta=38^{\circ}$, attributable to metallic silver. Trace amount of $\beta$-TCP phase (JCPDS 9-16) 
was observed in all the samples. The degree of crystallinity, the lattice parameters and crystallite sizes are presented in Table 1. The lattice parameters $a$ and $c$ increased with increasing $\mathrm{Ag}$ concentration. Changes in cell parameters may imply that silver substituted calcium in the HAp lattice and since $\mathrm{Ag}^{+}(0.128 \mathrm{~nm})$ is larger than $\mathrm{Ca}^{2+}(0.099 \mathrm{~nm})$ it resulted in increase in lattice parameters (Rameshbabu and Prasad Rao 2007; Stanic et al. 2011).

Figure 2, shows the FTIR spectra of HAp and Ag-HAp samples. The characteristic signature HAp double bands near $600 \mathrm{~cm}^{-1}$ are attributed to the bending modes of $\mathrm{P}-\mathrm{O}$ bonds in phosphate groups with contribution from the $-\mathrm{OH}$ of the apatite group at about $630 \mathrm{~cm}^{-1}$ (Ramanan and Venkatesh 2004). The bands in the region $3300 \mathrm{~cm}^{-1}$ are attributed to $-\mathrm{OH}$ bonds and those observed near $3,571 \mathrm{~cm}^{-1}$ are associated with $\mathrm{OH}^{-1}$ stretching vibration of HAp (Tas 2000). The broad band extending from 2,500 to about $3,700 \mathrm{~cm}^{-1}$ and the band at about $1,635 \mathrm{~cm}^{-1}$ corresponds to absorbed water (Stanic et al. 2011). The bands noted around $1,100-1,000 \mathrm{~cm}^{-1}$ are assigned to the stretching modes of the $\mathrm{PO}_{4}{ }^{3-}$ bonds in HAp (Smith 1999). The strongest band between 1,020 to $1,100 \mathrm{~cm}^{-1}$, which appeared as a doublet or a band with a shoulder, in all samples was due to the $\mathrm{P}-\mathrm{O}$ stretching vibration of the phosphate group (Stanic et al. 2011).

The TEM micrographs (Fig. 3) show particles of uniform size distribution with elongated rod-like morphology independent of the dopant concentration. The length of the nanorods varied from $110-180 \mathrm{~nm}$ and the diameter was between 20 and $25 \mathrm{~nm}$. Silver aggregates on HAp particles have been reported during synthesis of Ag-HAp nanocomposites, using a colloidal chemical route and subsequent reduction in $\mathrm{H}_{2} / \mathrm{Ar}$ atmosphere at $350{ }^{\circ} \mathrm{C}$. This has been attributed to partial destabilization of HAp in aqueous suspension favoring the growth of $\mathrm{Ag}_{2} \mathrm{O}$ nuclei (Diaz et al. 2009). Chung et al. (2006) also reported the presence of $\mathrm{Ag}_{2} \mathrm{O}$ crystallite phase in addition to the HAp and the nitrate phases, depending upon the degree of substitution by silver. In this procedure no such formation of $\mathrm{Ag}_{2} \mathrm{O}$ nuclei was detected.

Antimicrobial studies were carried out against two representative pathogenic organisms, Gram-negative E. coli and Gram-positive S. aureus. It was observed that all the AgHAp samples (1,3 and $5 \%$ ) exhibited antimicrobial activity; however, no inhibition was obtained for the pure HAp. The zones of inhibition obtained are shown in Fig. 4. It was observed that $3 \% \mathrm{Ag}-\mathrm{HAp}$ exhibited maximum activity as compared to 1 and $5 \% \mathrm{Ag}$-HAp for both the test organisms. Antimicrobial activity of Ag-HAp based compounds such as plasma sprayed silver containing HAp coatings on Ti plates (Chen et al. 2008), magnetron co-sputtered silver containing HAp coatings (Chen et al. 2006), Ag-nHAp/ $\mathrm{TiO}_{2} / \mathrm{PA} 66$ scaffolds (Xia et al. 2010), silver-hydroxyapatite/titania film on titanium plates (Mo et al. 2008) and HAp self assembled calcium phosphate glasses (Simon et al. 2008) has been attributed to the $\mathrm{Ag}$ ions released into the medium. It is well known that silver ions and silver based compounds can destroy cell membranes and cell walls of bacteria and affect their growth (Woo et al. 2008; Furr et al. 1994). In order to estimate the concentration of Ag ions that are released when $\mathrm{Ag}-\mathrm{HAp}$ is suspended in aqueous medium, ICP-MS studies were carried out. It was observed that the amount of silver
Fig. 1 XRD Micrograph of HAp, $1 \%$ Ag-HAp, $3 \%$ Ag-HAp and $5 \%$ Ag-HAp
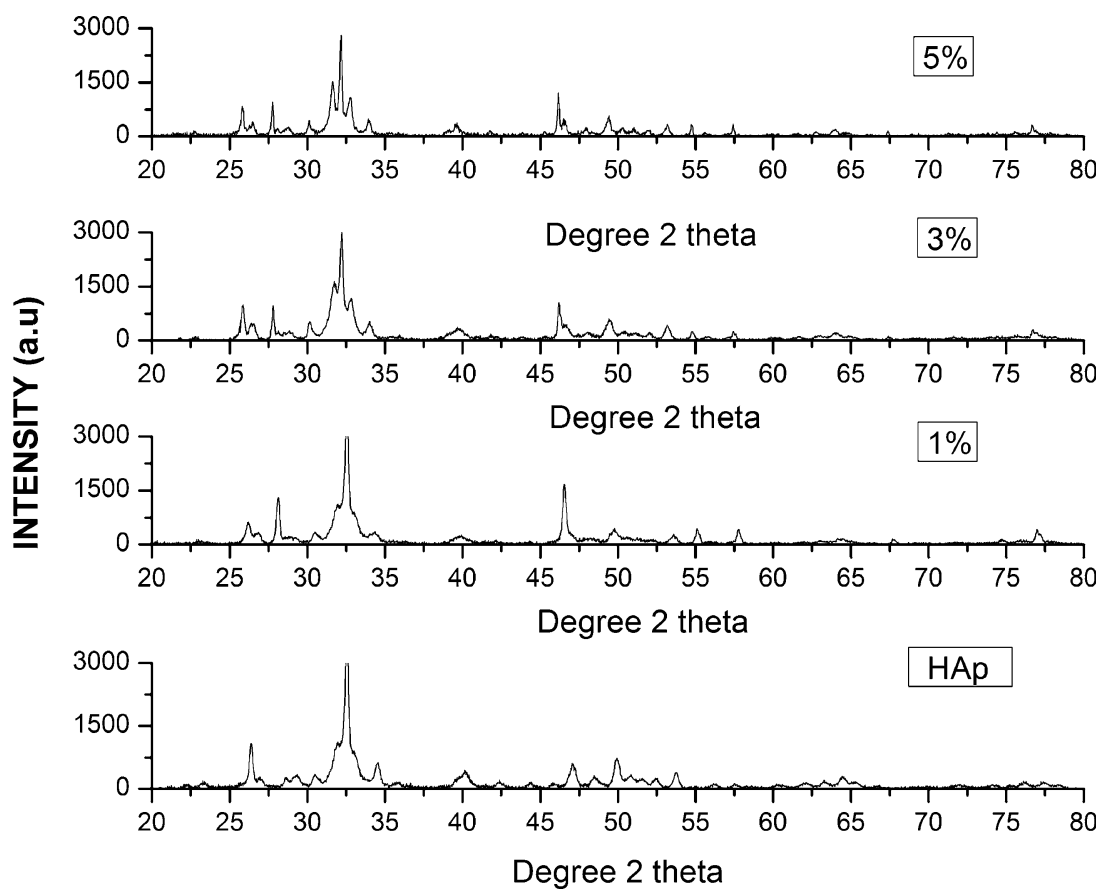
Table 1 Crystallite size, degree of crystallinity and unit cell parameters of HAp and Ag-HAp nanorods

\begin{tabular}{lllll}
\hline & Crystallite size $X_{\mathrm{s}}(\mathrm{nm})$ & Degree of crystallinity $X c$ & \multicolumn{2}{c}{ Unit cell parameters } \\
\cline { 4 - 5 } & & & $a$-axis $(\AA)$ & $c$-axis $(\AA)$ \\
\hline HAp & 10 & 0.216 & 9.3550 & 6.1490 \\
$1 \%$ Ag-HAp & 31 & 0.027 & 9.5144 & 6.7108 \\
$3 \%$ Ag-HAp & 24.89 & 0.064 & 9.5753 & 6.7140 \\
$5 \%$ Ag-HAp & 38.7 & 0.110 & 9.3630 & 6.7996 \\
\hline
\end{tabular}
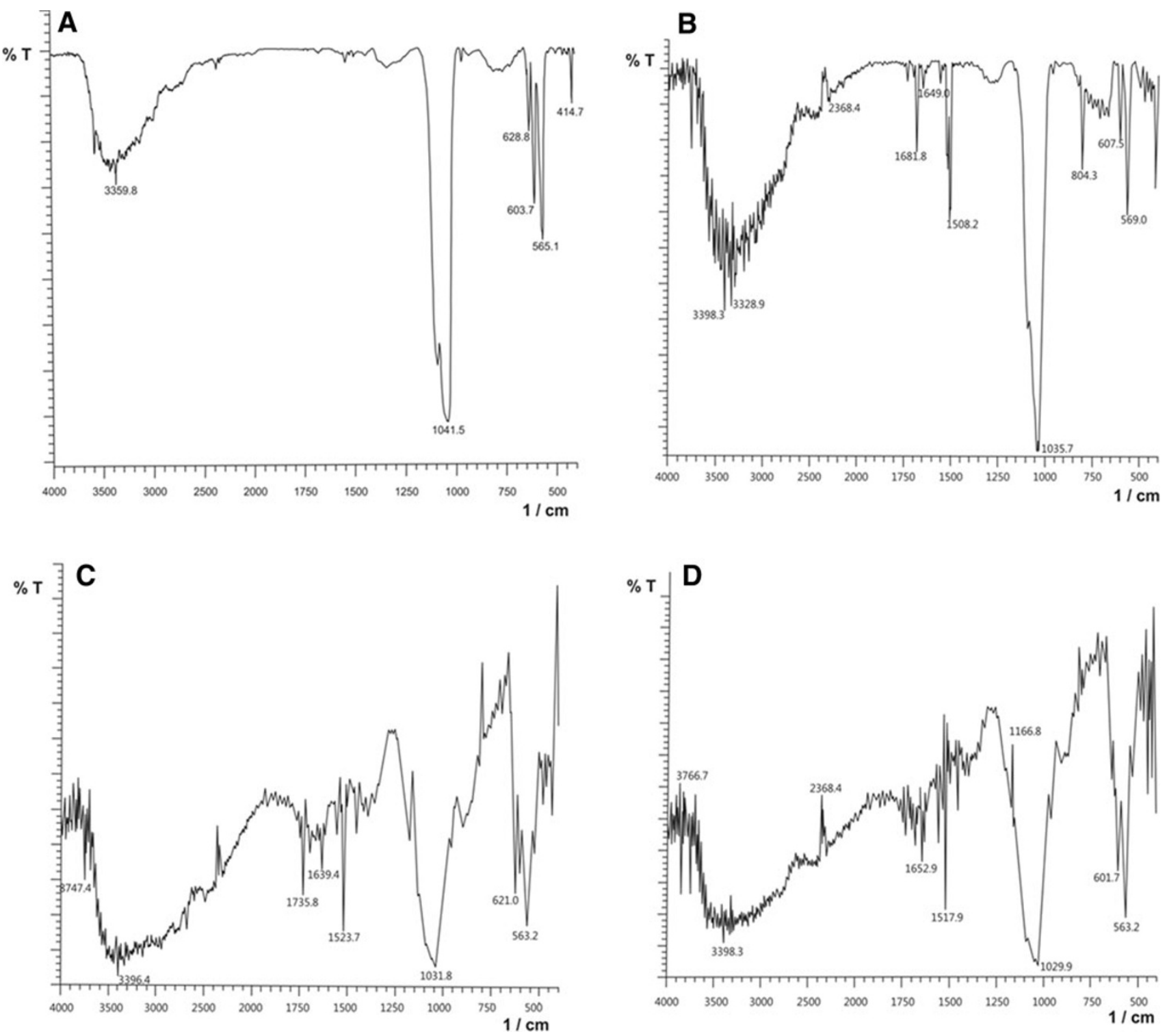

Fig. 2 FTIR graphs of a HAp b $1 \%$ Ag-HAp c $3 \%$ Ag-HAp d $5 \%$ Ag-HAp

leached out from all the three samples was almost the same and in the range of 406-499 $\mathrm{ng} / \mathrm{ml}$ after $1 \mathrm{~h}$. No further increase in the release of $\mathrm{Ag}$ ion was noted even after $24 \mathrm{~h}$. Thus, negligible amount of silver ions (1-4\%) were released from the silver present in the Ag-HAp samples. However, the antimicrobial activity in case of $3 \% \mathrm{Ag}$-HAp was higher than that of 1 and $5 \%$ Ag-HAp. Hence, the antimicrobial activity cannot be solely attributed to the leaching of $\mathrm{Ag}$ ions into the media. Dissolution of the HAp matrices can increase the availability of $\mathrm{Ag}$ ions for antimicrobial action. The solubility of HAp at the solid liquid interface depends on its physicochemical properties, types and amounts of foreign 
Fig. 3 TEM Micrographs of a HAp b $1 \%$ Ag-HAp c $3 \%$ Ag-HAp d $5 \%$ Ag-HAp
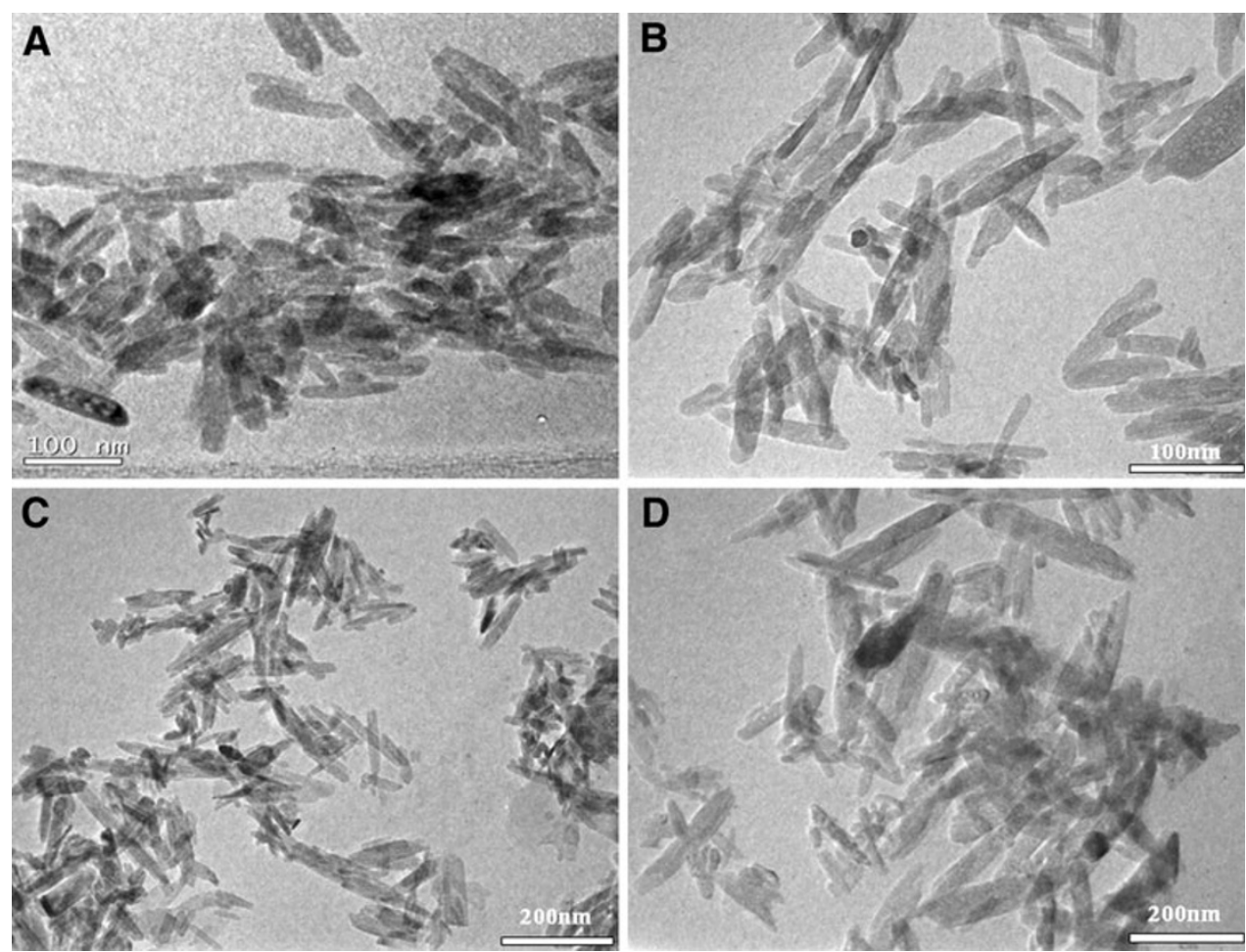

ions present in its structure and the type of solution (Stanic et al.2011). The degree of cyrstallinity also affects the solubility behavior of HAp. The dissolution property of the HAp coatings in Tris buffer has shown that coatings having high crystallinity had low dissolution rate compared to that of low crystallinity (Xue et al. 2004). In accordance with these results, $5 \%$ Ag-HAp, had high crystallinity (Table 1), hence lower solubility and lower rate of dissolution. $3 \% \mathrm{Ag}$ HAp had low crystallinity compared to $5 \%$, thus better rate of dissolution, and better antimicrobial activity, as indicated by the larger zone of inhibition in disc diffusion assay. These results have been corroborated by the MIC studies as discussed below. Low antimicrobial activity observed in $1 \%$ Ag-HAp can be ascribed to the low amount of silver present in the samples.

MIC is noted as the lowest concentration of an antimicrobial substance that will inhibit the visible growth of a microorganism after $24 \mathrm{~h}$ of incubation and $\mathrm{MBC}$ is the lowest concentration required to kill all the organisms. The MBC by MIC ratio is a parameter that reflects the bactericidal capacity of a compound in terms of bacterial susceptibility, tolerance or resistance to the agent being tested. With an MBC: MIC ratio <4.0, it has been shown that silver nanoparticles act as a bactericide against $S$. aureus (Nunez et al. 2009). In the present work, the MIC and MBC concentrations of Ag-HAp on different media were determined using the REMA method wherein Resazurin, an oxidation-reduction indicator, is used for the evaluation of cell viability (Sarker and Nahar 2007). It is a blue non- fluorescent and non-toxic dye that becomes pink and fluorescent when reduced to resorufin by oxido-reductases within viable cells (Landi et al. 2000). Antimicrobial activity for $\mathrm{Ag}$ nanoparticles is reported in the range $1.69-100 \mu \mathrm{g} / \mathrm{ml}$ for various bacterial cultures (MarambioJones and Hoek 2010; Kvitek et al. 2008; Kim et al. 2011; Sondi and Sondi 2004). Silver based HAp nanocomposites have been shown to exhibit antimicrobial activity in growth medium where the Ag concentration ranges from 10 to $70 \mu \mathrm{g} / \mathrm{ml}$ for Gram-negative and Gram-positive cultures (Diaz et al. 2009; Rameshbabu and Prasad Rao 2007). In this study, Ag-HAp exhibited antimicrobial activity at a much lower silver concentration of $7 \mu \mathrm{g} / \mathrm{ml}$ against $E$. coli and at $15 \mu \mathrm{g} / \mathrm{ml}$ for $S$. aureus. The bactericidal concentration of $1 \%$ Ag-HAp for E. coli and S. aureus could not be determined on $\mathrm{MH}$ medium as the Ag-HAp was found to be bacteriostatic even at the highest concentration feasible for testing $(1,500 \mu \mathrm{g} / \mathrm{ml})$; effective $\mathrm{Ag}$ concentration (EAC) of $17 \mu \mathrm{g} / \mathrm{ml}$. In case of E. coli, the MIC for $3 \% \mathrm{Ag}$ HAp was $200 \mu \mathrm{g} / \mathrm{ml}$ (EAC: $7 \mu \mathrm{g} / \mathrm{ml}$ ) and for $5 \%$ Ag-HAp it was $160 \mu \mathrm{g} / \mathrm{ml}$ (EAC is $8.8 \mu \mathrm{g} / \mathrm{ml})$. Similar results were obtained for $S$. aureus, wherein the MIC values for 3 and $5 \%$ Ag-HAp were $450 \mu \mathrm{g} / \mathrm{ml}$ (EAC: $15 \mu \mathrm{g} / \mathrm{ml}$ ) and $300 \mu \mathrm{g} / \mathrm{ml}$ (EAC: $16.2 \mu \mathrm{g} / \mathrm{ml})$, respectively. Table 2 shows the MIC and MBC values obtained in both the media. MICs obtained in MH broth were higher than MICs in minimal medium. The profile of antimicrobial activity varied when MIC and MBC studies were carried out in minimal medium (M9 medium). MIC against E. coli for 
Fig. 4 a, b: Disc diffusion test results of $a$ HAp $b 1 \% \mathrm{Ag}$ - HAp c $3 \%$ Ag-HAp $d 5 \%$ Ag-HAp against $E$. coli and $S$. aureus respectively
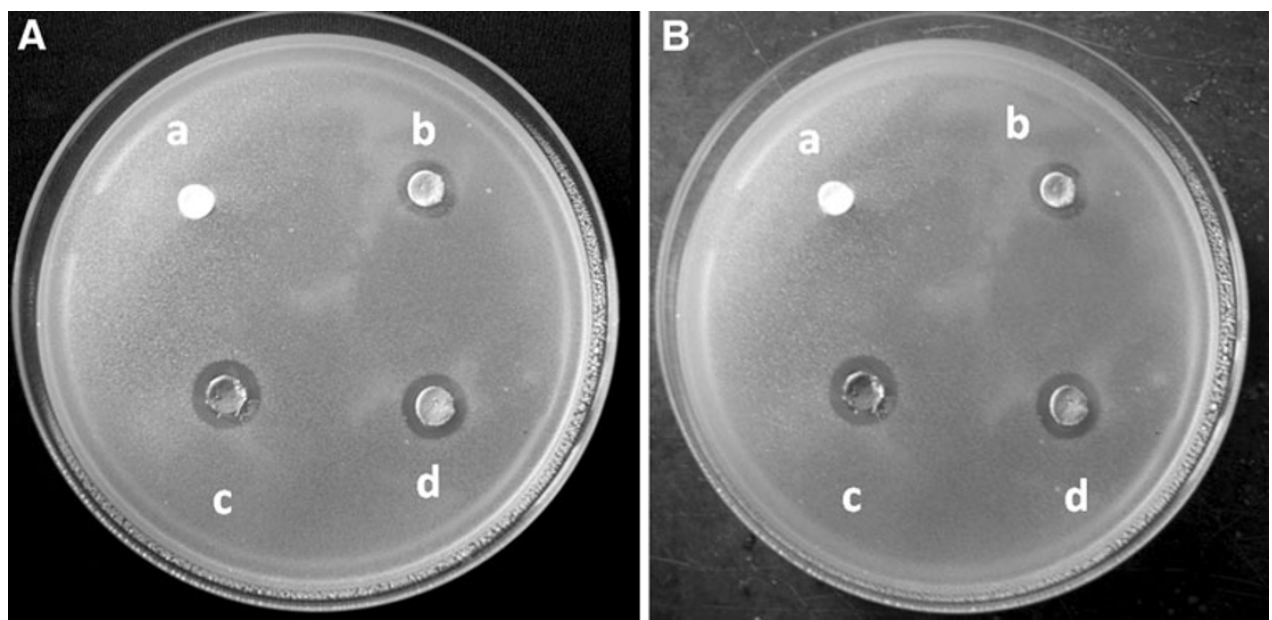

$1 \%$ was $10 \mu \mathrm{g} / \mathrm{ml}$ (EAC: $0.11 \mu \mathrm{g} / \mathrm{ml}$ ), $3 \%$ was $3 \mu \mathrm{g} / \mathrm{ml}$ (EAC: $0.10 \mu \mathrm{g} / \mathrm{ml}$ ) and $5 \%$ Ag-HAp was $2 \mu \mathrm{g} / \mathrm{ml}$ (EAC: $0.11 \mu \mathrm{g} / \mathrm{ml}$ ). Similar results were obtained for $S$. aureus wherein MIC values for 1,3 and $5 \%$ were $15 \mu \mathrm{g} / \mathrm{ml}$ (EAC: $0.14 \mu \mathrm{g} / \mathrm{ml}$ ), $4 \mu \mathrm{g} / \mathrm{ml}$ (EAC: $0.11 \mu \mathrm{g} / \mathrm{ml}$ ), $3 \mu \mathrm{g} / \mathrm{ml}$ (EAC: $0.165 \mu \mathrm{g} / \mathrm{ml}$ ), respectively. This shows that components of rich medium may exert protective action on the cells in the presence of silver. It has been reported that MICs and MBCs against bacteria using Ag based antimicrobial agent differs greatly with media composition (Borghee et al. 2004). In nutrient rich media, metal ions such as silver, copper etc. have been shown to form oxides, hydroxides or inorganic salts with the media components thereby limiting their activity against the organisms, therefore, decreasing their antimicrobial efficiency (Yoshiki et al. 2010).

It has also been observed that Ag-HAp exhibits better activity against Gram-negative E. coli as compared to $S$. aureus. This difference in the susceptibility is due to the differences in their cell wall components. Gram-negative organisms have an outer membrane with negative charge on the surface, which is not present in the Gram-positive organisms. Silver ions thus have stronger affinity towards the cell wall of Gram-negative organisms as compared to Gram-positives. Interaction of silver ions with biological membranes causes the production of ROS which damages the cell membrane (Russell et al. 1996; Dibrov et al. 2002; Dragieva et al. 1999). Silver ions react with various cytosomal proteins, ribosomes and nucleic acids, thus preventing replication and translation, eventually causing cell death (Kim et al. 1998; Klasen 2006). It is also known to interfere with the trans-membrane electron transport, block respiratory chain at the cytochromes and cause metabolic flux inducing a proton leakage through the bacterial cell wall (Kim et al. 1998; Klasen 2006). In comparison to other metals with antimicrobial properties, silver has the most effective antibacterial action and the least toxicity to animal cells (Guggenbichler et al. 1999).

The MBC studies also showed better activity for the $3 \%$ Ag-HAp (Table 2). The reduction in the number of microorganisms on exposure to $\mathrm{MBC}$ concentration of $\mathrm{Ag}$ HAp with respect to time is shown in Fig. 5. For HAp, 3 and $5 \% \mathrm{Ag}-\mathrm{HAp}$, it was observed that from an initial concentration of $1 \times 10^{6}$ cells $/ \mathrm{ml}$, a complete reduction in the number of viable cells was obtained for $E$. coli and a reduction of 99.97 and $98 \%$, respectively, was obtained against $S$. aureus, within $2 \mathrm{~h}$ of exposure.

Hemolysis is an important factor to assess the biocompatibility of a material (Xiao et al. 2010). Hemolytic assays are performed to examine interaction of nanoparticles with red blood cell membranes by measuring the released hemoglobin. HAp particles interact with numerous cellular systems in vivo and some of these interactions may lead to damaged cells and stimulate platelet activation, coagulation and thrombus formation (Wiessner et al. 1988; Quan

Table 2 MIC, MBC values of 1, 3, $5 \%$ Ag-HAp in MH and M9 minimal media against E. coli, S. aureus

\begin{tabular}{|c|c|c|c|c|c|c|c|c|c|c|c|c|}
\hline \multirow[t]{3}{*}{$\%$} & \multicolumn{6}{|l|}{ E. coli } & \multicolumn{6}{|c|}{ S. aureus } \\
\hline & \multicolumn{3}{|c|}{ Muller Hinton broth } & \multicolumn{3}{|c|}{ M9 minimal media } & \multicolumn{3}{|c|}{ Muller Hinton Media } & \multicolumn{3}{|c|}{ M9 minimal media } \\
\hline & $\begin{array}{l}\text { MIC } \\
(\mu \mathrm{g} / \mathrm{ml})\end{array}$ & $\begin{array}{l}\mathrm{MBC} \\
(\mu \mathrm{g} / \mathrm{ml})\end{array}$ & $\begin{array}{l}\mathrm{MBC} / \\
\mathrm{MIC}\end{array}$ & $\begin{array}{l}\text { MIC } \\
(\mu \mathrm{g} / \mathrm{ml})\end{array}$ & $\begin{array}{l}\mathrm{MBC} \\
(\mu \mathrm{g} / \mathrm{ml})\end{array}$ & $\begin{array}{l}\mathrm{MBC} / \\
\mathrm{MIC}\end{array}$ & $\begin{array}{l}\text { MIC } \\
(\mu \mathrm{g} / \mathrm{ml})\end{array}$ & $\begin{array}{l}\mathrm{MBC} \\
(\mu \mathrm{g} / \mathrm{ml})\end{array}$ & $\begin{array}{l}\mathrm{MBC} / \\
\mathrm{MIC}\end{array}$ & $\begin{array}{l}\text { MIC } \\
(\mu \mathrm{g} / \mathrm{ml})\end{array}$ & $\begin{array}{l}\mathrm{MBC} \\
(\mu \mathrm{g} / \mathrm{ml})\end{array}$ & $\begin{array}{l}\text { MBC/ } \\
\text { MIC }\end{array}$ \\
\hline 1 & $>1,500$ & $>1,500$ & 1 & 10 & 15 & 1.5 & $>1,500$ & $>1,500$ & 1 & 17 & 23 & 1.35 \\
\hline 3 & 220 & 240 & 1.09 & 3 & 5 & 1.66 & 450 & 475 & 1.05 & 4 & 6 & 1.5 \\
\hline 5 & 160 & 180 & 1.12 & 2 & 3 & 1.5 & 300 & 350 & 1.16 & 3 & 4 & 1.33 \\
\hline
\end{tabular}


Fig. 5 Kill curve studies against a $E$. coli $\mathbf{b} S$. aureus

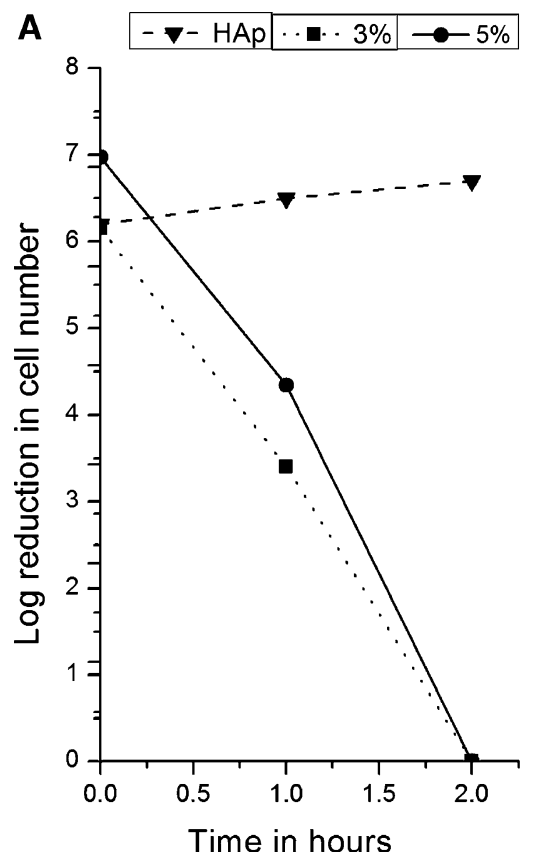

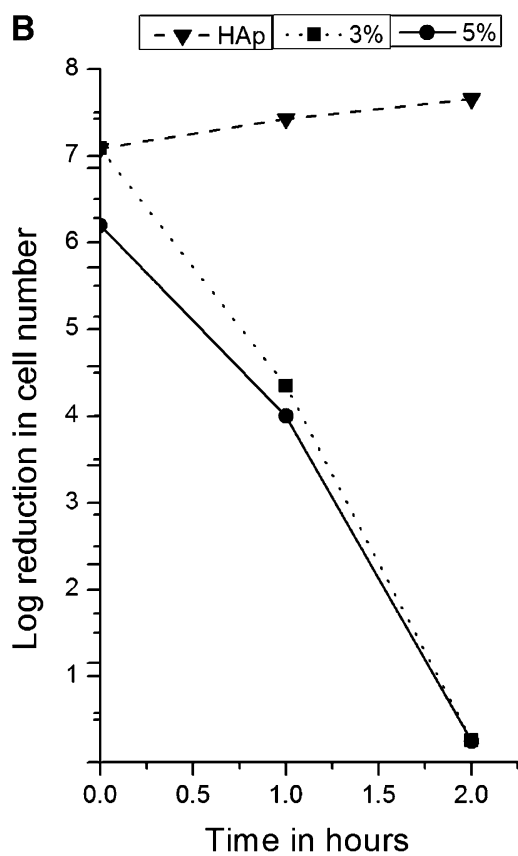

Table 3 Hemolytic ratio (HR) of 1, 3, $5 \%$ Ag-HAp

\begin{tabular}{ll}
\hline Samples & HR (\%) \\
\hline HAp & 1.14 \\
$1 \%$ Ag-HAp & 1.411 \\
$3 \%$ Ag-HAp & 1.38 \\
$5 \%$ Ag-HAp & 9.3 \\
\hline
\end{tabular}

et al. 2008). The hemolysis rate for 1 and $3 \%$ Ag-HAp were estimated to be $\sim 1.4 \%$, whereas in case of $5 \% \mathrm{Ag}$ HAp a much higher rate of $9.3 \%$ was observed (Table 3 ). According to ASTM F 756-00, samples with hemolysis rate less than $2 \%$ can be considered nonhemolytic thus 1 and $3 \%$ Ag-HAp are suitable for biomedical applications. It has been shown that the hemolysis rate is influenced by the silver concentration and the degree of crystallinity, with the latter having a more dominating influence on hemolysis (Chen et al. 2006; Stanic et al. 2011; Wiessner et al. 1988).

\section{Conclusion}

In this study, a simple low temperature method of synthesizing Ag-HAp nanorods using a modified sol-gel technique has been reported. XRD, TEM, FTIR studies have shown that the compounds synthesized are pure, rod shaped crystalline Ag-HAp nanoparticles. Antimicrobial studies using disc diffusion assay and REMA method, against $E$. coli and $S$. aureus showed that $3 \%$ Ag-HAp exhibited maximum inhibition and hence is an ideal material to be used for biological applications. ICP-MS studies showed that most of the doped silver was retained within the material and released in very small amounts, which could facilitate sustained antimicrobial activity. The hemolysis ratio for 1 and $3 \% \mathrm{Ag}$-HAp were less than $1.4 \%$, indicating these to be hemocompatible and that of $5 \%$ Ag-HAp was $9.3 \%$ thereby making it non hemocompatible. The $3 \%$ Ag-HAp synthesized in this work, with its high antimicrobial activity and hemocompatibility, offers itself to be a promising bactericidal material which can be used for implant applications and for bone tissue engineering.

Acknowledgments We would like to thank Sophisticated Analysis Instrumentation Facility (SAIF), Indian Institute of Technology (IIT), Mumbai, for their help with TEM; Dr. Balaram, National Geographic Research Institute, Hyderabad, for his kind help and co-operation with ICP-MS and Dr. Lisette D'Souza, National Institute of Oceanography (NIO), Goa, for help with FTIR.

Open Access This article is distributed under the terms of the Creative Commons Attribution License which permits any use, distribution, and reproduction in any medium, provided the original author(s) and the source are credited.

\section{References}

Babapour A, Akhavan O, Azimirad R, Moshfegh AZ (2006) Physical characteristics of heat-treated nano-silvers dispersed in sol-gel silica matrix. Nanotechnology 17:763-771

Bahadir A, Ergun C, Baydogan M (2009) Synthesis and characterization of Ag doped Hydroxylapatite as an antibacterial scaffold material. Defect Diffus Forum 283-286:250

Borghee R, Borsetti F, Foladori P, Ziglio G, Zannoni D (2004) Effects of the metalloid oxyanion tellurite on growth characteristics of the phototrophic bacterium Rhodobacter capsulatus. Appl Environ Microbiol 70(11):6595-6602 
Bragg PD, Rainnie DJ (1974) The effect of silver ions on the respiratory chain of Escherichia coli. J Microbiol 20(6):883-889

Chen W, Liu Y, Curtney HS, Bettenga M (2006) In vitro anti-bacterial and biological properties of magnetron co-sputtered silvercontaining hydroxyapatite coating. Biomaterials 27:5512-5517

Chen Y, Zheng X, Xie Y, Ding C, Ruan H, Fan C (2008) Antibacterial and cytotoxic properties of plasma sprayed silvercontaining HA coating. J Mater Sci Mater Med 19:3603-3609

Chung RJ, Ming FH, Huang CW, Perng LH, Wen HW, Chin TS (2006) Antimicrobial effects and human gingival biocompatibility of hydroxyapatite sol-gel coatings. J Biomed Mater Res B Appl Biomater 76:169-178

Diaz M, Barba F, Miranda M, Guitian F, Torrecillas R, Moya SJ (2009) Synthesis and antimicrobial activity of a silver hydroxyapatite nanocomposite. J Nanomater. doi:10.1155/2009/498505

Dibrov P, Dzioba J, Gosink KK, Hase CC (2002) Chemiosmotic mechanism of antimicrobial activity of $\mathrm{Ag}$ in vibrio cholera. Antimicrob Agents Chemother 46:2668-2670

Dragieva I, Stoeva S, Stoimenov P, Pavlikianov E, Klabunde K (1999) Complex formation in solutions for chemical synthesis of nanoscaled particles prepared by borohydride reduction process. Nanostruct Mater 12:267-270

Feng QL, Wu J, Chen GQ, Cui FZ, Kim TN, Kim JO (2000) A Mechanistic study of the antibacterial effect of silver ions on Escherichia coli and Staphylococcus aureus, J Biomed Mater Res 52:662-668

Furr JR, Russell AD, Turner TD, Andrews A (1994) Antibacterial activity of Actisorb Plus, Actisorb and silver nitrate. J Hosp Infect 27(3):201-208

Gristina AG, Costerton JW (1985) Bacterical adherence to biomaterials and tissue: the significance of its role in clinical species. J Bone Joint Surg Am 67:264-273

Guggenbichler JP, Boswald S, Lugauer Krall T (1999) A new technology of microdispersed silver in polyurethane induces antimicrobial activity in central venous catheters. Infection 27:S16-S23

Hyung JJ, Sung CY, Seong GO (2003) Preparation and antibacterial effects of $\mathrm{Ag}-\mathrm{SiO} 2$ thin films by sol-gel method. Biomaterials 24:4921-4928

Jadalannagari S, More S, Kowshik M, Ramanan SR (2011) Low temperature synthesis of hydroxyapatite nanorods using a modified sol-gel technique. Mater Sci Engg C 31:1534-1538

Kim TN, Feng QL, Kim JO, Wu J, Wang H, Chen GC, Cui FZ (1998) Antimicrobial effects of metal ions $\left(\mathrm{Ag}^{+}, \mathrm{Cu}^{2+}, \mathrm{Zn}^{2+}\right)$ in hydroxyapatite. J Mater Sci Mater Med 9:129-134

Kim SH, Lee HS, Ryu DS, Choi SJ, Lee DS (2011) Antibacterial activity of silver-nanoparticles against Staphylococcus aureus and Escherichia coli, Korean. J Microbiol Biotechnol 39:77-85

Klasen JH (2006) A historical review of the use of silver in treatment of burns. II. Renewed interest for silver. Burns 26:131-138

Kramer SJ, Spadaro JA, Webster DA (1981) Antibacterial and osteoinductive properties of demineralized bone matrix treated with silver. Clin Orthop Relat Res 16:1154-1162

Kvitek L, Panacek A, Soukupova J, Kolar M, Vecerova R, Prucek R, Holecova M, Zboril R (2008) Effect of surfactants and polymers on stability and antibacterial activity of silver nanoparticles (NPs). J Phys Chem C 112:5825

Landi E, Tampieri A, Celotti G, Spiro S (2000) Densification behavior and mechanisms of synthetic hydroxyapatite. J Eur Ceram Soc 20:2377-2387

Marambio-Jones C, Hoek EMV (2010) A review of the antibacterial effects of silver nanomaterials and potential implications for human health and the environment. J Nanopart Res 12(5):1531-1551

Mo A, Liao J, Xu W, Xian S, Li Y, Bai S (2008) Preparation and antibacterial effect of silver-hydroxyapatite/titania nano composite thin film on titanium. Appl Surf Sci 255:435-438
Nunez NN, Villegas H, Turrent L, Padilla C (2009) Silver nanoparticles toxicity and bactericidal effect against methicillin resistant staphylococcus aureus nanoscale does matter. Nanobiotechnol 5:2-9

Quan R, Yang D, Wu X, Wang H, Miao X, Li W (2008) In vitro biocompatibility of graded hydroxyapatite-zirconia composite bioceramic. J Mater Sci Mater Med 19:183-187

Ramanan SR, Venkatesh R (2004) A study of hydroxyapatite fibers prepared via sol-gel route. Mat Lett 58:3320-3323

Rameshbabu N, Sampath Kumar TS, Prabhakar TG, Sastry VS, Murty KVGK, Prasad Rao K (2007) Antibacterial nanosized silver substituted hydroxylapatite: Synthesis and characterization. J Biomed Mater Res A 80:581-591

Russell SW, Luptak KA, Suchicital CTA, Alford TL, Pizziconi VB (1996) Chemical and structural evolution of sol-gel derived hydroxyapatite thin films under rapid thermal processing. J Am Ceram 79:837-842

Sambrook J, Russell D (2001) Molecular cloning: a laboratory manual. Cold Spring Harbor: Cold Spring Harbor Laboratory

Sarker SD, Nahar L, Kumarasamy Y (2007) Microtitre plate based antibacterial assay incorporating resazuring as an indicator of cell growth, and its application in the in vitro antibacterial screening of phytochemicals. Methods 42(4):321-324

Schreus WJA, Rosenberg H (1982) Effect of silver ions on transport and retention of phosphate by Escherichia coli. J Bacteriol $152: 7-13$

Simon V, Albon C, Simon S (2008) Silver release from hydroxyapatite self assembling calcium phosphate glasses. J Non-cry Sol 354:1751-1755

Smith B (1999) Infrared spectral interpretation: a systematic approach.CRC press, USA

Sondi I, Sondi BS (2004) Silver nanoparticles as antimicrobial agent: a case study on E. coli as a model for Gram-negative bacteria. J Colloid Interface Sci 275:117-182

Stanic V, Janackovic D, Dimitrijevic S, Tanaskovic BS, Mitric M, Pavlovic SM, Krstic A, Jovanovic D, Raicevic S (2011) Synthesis of antimicrobial monophase silver-doped hydroxyapatite nanopowders for bone tissue engineering. Appl Surf Sci 257:4510-4518

Tas AC (2000) Synthesis of biomimetic Ca-Hydroxyapatite powders at $37{ }^{\circ} \mathrm{C}$ in synthetic body fluids. Biomaterials 21:1429-1438

Wiessner J, Mandel G, Halverson P, Mandel N (1988) The effect of hydroxyapatite crystallinity on hemolysis. Calcif Tissue Int 42:210-219

Woo K. J, Hye CK, Ki WK, Sook S, So H, K, Yong HP (2008) Antibacterial activity and mechanism of action of the silver ion in Staphylococcus aureus and Escherichia coli, Appl Enviorn Microb 74:2171-2178

Xia W, Li J, Wang L, Huang D, Zuo Y, Yubao L (2010) The release properties of silver ions from Ag-nHA/TiO2/PA66 antimicrobial composite scaffolds. Biomed Mater 5:044105

Xiao B, Karren M, Christopher MR, Rabiei A (2010) Functionally graded hydroxyapatite coatings doped with antibacterial components. Acta biomaterialia 6:2264-2273

Xue W, Tao S, Liu X, Zheng X, Ding C (2004) In vivo evaluation of plasma sprayed hydroxyapatite coatings having different crystallinity. Biomaterials 25:415-421

Yoshiki A, Hiroshi M, Iwao N, Fumiaki M, Takafumi S, Yutaka Y, Masaki M, Takao H (2010) Effect of bacterial media on the evaluation of the antibacterial activity of biomaterial containing inorganic antibacterial reagents or antibiotics. Biocontr Sci 15(1):15-19

Zheng X, Chen Y, Xie Y, Ji Heng, Huang L, Ding C (2009) Antibacterial property and biocompatibility of plasma sprayed hydroxyapatite/silver composite coatings. J Therm Spray Tech $16: 463$ 